\title{
SYNTAX FOR SPEECH-LANGUAGE PATHOLOGISTS
}

\section{Ondene van Dulm, Stellenbosch University}

\section{INTRODUCTION}

The general aim of this paper is to set out certain aspects of recent developments in the field of syntax, and to show how they are of particular relevance to the speech-language pathologist (SLP). The paper provides an introduction to this field, with a focus on that which may be applicable in clinical practice, and as such is targeted at SLPs who possess little or no understanding of current syntactic theory. As Shapiro (2000:2) notes, "understanding syntax and manipulating it in principled ways is becoming more and more important to the treatment of language disorders". With this in mind, the paper aims to provide SLPs with a basic understanding of current syntactic theory in order to equip them to utilise such knowledge in the clinical process. By way of introduction, section 2 provides an overview of the development of the field of syntactic theory from the early days of generative grammar (Chomsky 1957; 1964; 1965) to current work within the minimalist program (Chomsky $1995 \mathrm{a} ; 1999 ; 2000 ; 2001 ; 2002)$. The aim of this overview is to orientate the reader with regard to what follows in sections 3 and 4, perhaps bridging the gap between vague memories of generative syntax in undergraduate linguistics courses and current issues in the clinical application of syntax discussed in recent papers on the topic. In section 3, central aspects of current syntactic theory which are particularly relevant to application in clinical practice are set out. In section 4, examples of the successful application of syntax in informing the clinical process are discussed.

\section{GENERATIVE GRAMMAR: AN OVERVIEW}

\subsection{Generative Grammar}

Early work within the framework of generative grammar (cf. Chomsky 1957; 1964; 1965) has in part been motivated by the Humboldtian view on the nature, use, and acquisition of language. This view entails that the ability to use a language is dependent on the speakerhearer's development of an internal representation of the "form" of the language, this form 
being a system of generative rules that determine the structure ("the manner of formation") of linguistic utterances (Chomsky 1964:17, 19, 24). Early work in generative grammar approached structural variation among languages along traditional lines (Chomsky 1995a:170), which entailed that researchers focused on particular syntactic phenomena ${ }^{1}$ in particular languages and proposed rules to account for these phenomena. According to this perspective, each language was thought to comprise a set of construction-specific and language-specific rules ${ }^{2}$. The aim of a descriptive grammar was then to represent the abovementioned system of generative rules underlying the structure of utterances. The term "generative grammar" was used by Chomsky (1964:9) to refer to a device that "specifies the infinite set of well-formed sentences and assigns to each of these one or more structural descriptions", where a structural description specifies the linguistic elements of an utterance and their structural relations. From the beginning, however, there was a preference within generative grammar for simpler syntactic analyses over more complex ones, for the smallest possible number of rules and the smallest possible number of elements. This preference for simplicity was, according to Belletti and Rizzi (2002:31), the basis upon which researchers selected among competing analyses of particular syntactic phenomena. Simplicity can thus be seen as another motivation behind work in generative grammar (in addition to the abovementioned Humboldtian view of language).

Tomalin $(2003: 1243,1244)$ notes that the desire for simplicity was reflected in Chomsky's earliest work, namely his 1951 MA thesis on the morphophonemics of Modern Hebrew, where he emphasised the need for a grammar to meet such requirements as simplicity and economy $^{3}$. Subsequent works (cf. Chomsky 1957; 1964; 1965) also emphasised the need for theory-internal simplicity, where the requirement of simplicity holds for any hypothesis or theory concerning the nature of the device that underlies generative grammar (Chomsky 1965:38, 39). The preference for simplicity can also be seen to dominate recent work in the generative tradition. Indeed, according to Chomsky (2002:95) and Tomalin (2003:1251), the increasing emphasis on economy and simplicity have led to the development of the minimalist program, discussed in section 2.3.

Research in the generative tradition is carried out against the background of the three levels of success for grammatical description that were laid down by Chomsky $(1964: 28,29)$. The 
lowest level of success is that of observational adequacy, attained when the grammar correctly characterises specific observed linguistic data (e.g., that in a corpus). The second level is descriptive adequacy, attained when a grammar additionally provides an account of the speaker-hearer's linguistic intuitions and offers meaningful generalisations expressing the underlying regularities of the observed linguistic data. The third level of success is that of explanatory adequacy, attained when the theory associated with the grammar presents an explanation for the linguistic intuitions of the speaker-hearer and, crucially, also for how principles underlying these intuitions could have been acquired. Within the tradition of generative grammar, then, an adequate theory is one which attains all three levels of success.

The progression of theories within early generative grammar can be summarised as follows: (i) classical theory (cf. Chomsky 1957), (ii) standard theory (cf. Chomsky 1964; 1965), (iii) extended standard theory (cf. Chomsky 1970), within which X-bar theory ${ }^{4}$ played a central role, and (iv) the principles and parameters theoretical framework (cf. section 2.2), within which Government and Binding (GB) theory (cf. p. 25) played a central role (cf. Chomsky $1981 ; 1986 a ; 1986 b)$.

\subsection{Principles and Parameters}

As mentioned above, early work within the framework of generative grammar led to the postulation of various rules, proposed to account for a multitude of syntactic phenomena in a wide variety of languages. Tension then arose between the needs for descriptive and explanatory adequacy, as it did not appear possible that a single grammar could simultaneously (i) account for the structures observed in individual languages (thereby attaining descriptive adequacy) and (ii) capture the fact that these structures derive from a single universally specified (innate) set of structures (thereby attaining explanatory adequacy). This tension, according to Chomsky (1995a:5), arose as "the goal of explanatory adequacy receded ... into the distance as generative systems were enriched in pursuit of descriptive adequacy". A quest for descriptive adequacy leads to greater and greater complexity and variety in systems of rules accounting for syntactic phenomena, different for each language, while that for explanatory adequacy requires the structure of different languages to be largely invariant (Chomsky 1997a:5). Questions as to how to resolve this tension led researchers to 
follow what has become known as the "principles and parameters" approach within generative grammar (cf. Chomsky 1981; 1986a; 1986b). Within the principles and parameters framework, the multitude of language-specific rules of the early generative tradition are replaced by principles and parameters that are assumed to be universally present, forming the basis of the language faculty. Thus, Chomsky (1995a:170) proposes that Universal Grammar (UG) provides a "system of principles and a finite array of finitely valued parameters". An example of a principle of UG is the Projection Principle, according to which a logical form $(\mathrm{LF})^{5}$ representation is projected from the lexicon via the syntax, in that such a representation observes the subcategorisation features of the lexical items of which it is comprised (Ouhalla 1999:111). A sentence like *John likes (where * indicates ungrammaticality ${ }^{6}$ ) is disallowed by this principle, as the subcategorisation feature of the verb like, namely [like: _ NP], whereby the verb takes a compulsory noun phrase (NP) complement, is not observed. John likes the cheese, in contrast, is well-formed according to the Projection Principle, as the NP complement the cheese satisfies the subcategorisation feature of like. An example of a parameter is the Head Parameter, which can have one of two values, making a given language either head-first or head-last (Ouhalla 1999:299). English is an example of a head-first language, in which the head of the phrase precedes the complement ${ }^{7}$, e.g. the verb ate precedes its object complement the cheese in Jack ate the cheese. Japanese, on the other hand, is an example of a head-last language, in which the head follows the complement, e.g. the preposition kara ("from") follows its complement gakko ("school") in sono gakuse-ga gakko kara modat ta (the student-NOMINATIVE school from return-PAST, meaning "the student returned from school") (O'Grady 1997:217).

These principles and parameters comprise the initial state of the language faculty, and each parameter can be set to a particular value ${ }^{8}$, on the basis of the input the speaker-hearer is exposed to. Each language L, then, is the result of the fixed set of principles and a certain configuration of parameter settings. This idea is illustrated in Figures 1a and b below. 


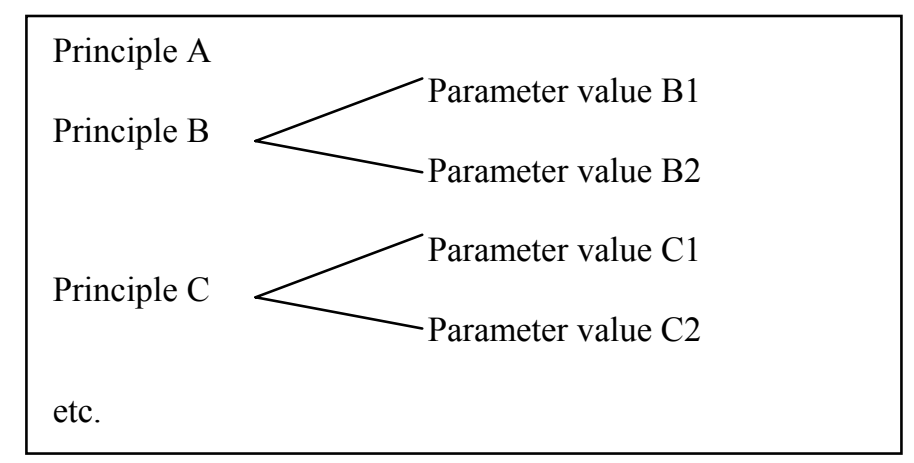

Figure 1a. The initial state of the language faculty

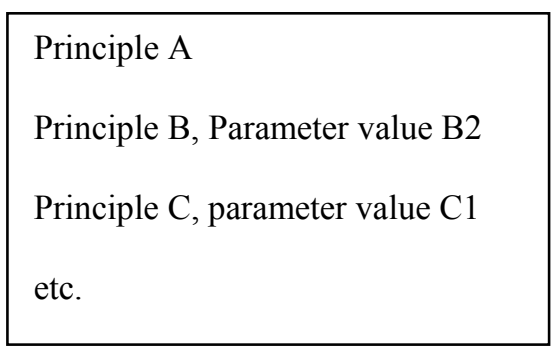

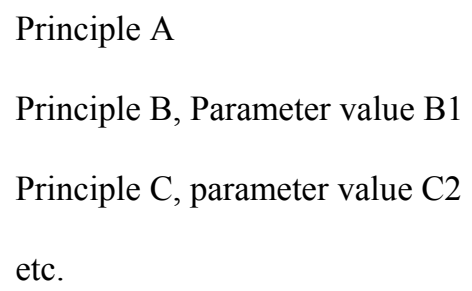

Figure $1 b$. Two examples of attained states of the language faculty

The principles and parameters framework provides a research program within which certain questions about the language faculty and languages are asked and answered in a certain way, the ultimate aim being to provide an account in terms of which all syntactic phenomena are shown to be the product of interaction between fixed and universal principles and languagespecific parameter settings. Thus, as Chomsky (1997a:6) notes, "the [principles and parameters - OvD] program suggests how the theory of language might satisfy the conflicting conditions of descriptive and explanatory adequacy".

GB theory was the most influential theory of grammar within the principles and parameters framework from the late 1970s to the early 1990s (cf. Chomsky 1981; 1986a; 1995a), and has been regarded as "the most fully worked out version of a principles and parameters approach to UG" (Hornstein, Nunes, and Grohmann 2001a:1). The government relation and the binding relation are central to this theory. Government entails the relation between a lexical head and its complement(s). For example, in Die man gee die bord vir sy vrou ("The man gives the plate to his wife"), the verb gee ("give") governs its complement die bord ("the plate"), and the preposition vir ("to") governs its complement sy vrou ("his wife"). The nouns man ("man"), bord ("plate") and vrou ("wife"), being lexical heads, are potential governors, but 
none has a complement to govern (cf. Cook and Newson 1996:241). Government is a fundamental relation in GB theory, and various mechanisms act within the domain of government (e.g. case assignment ${ }^{9}$, theta role assignment ${ }^{10}$, etc.). Government thus lends GB theory conceptual unity (cf. Hornstein, Nunes, and Grohmann 2001b:5). Binding is a structural relation governing the co-referencing properties of items in a sentence (Cook and Newson 1996:252). Specifically, there are three binding principles. The first states that an anaphor (such as himself) is bound in a local domain. Thus, himself in Charlie kicks $_{\text {himself }}$ is bound by its (co-indexed) antecedent Charlie. The second binding principle states that a pronominal (such as him) is free (i.e., not bound) in a local domain. Thus, him in Charlie kicks him is not bound by Charlie, which is not a co-indexed antecedent (thus, him cannot refer to Charlie). Finally, the third binding principle states that an r-expression is free (where r-expressions include names, such as Charlie, and other "referential" NPs, such as the dog in The dog bit her) (cf. Cook and Newson 1996: 250-252).

According to GB theory, there are four levels of grammatical representation, namely (i) deep structure (D-structure), (ii) surface structure (S-structure), (iii) logical form (LF), and (iv) phonetic form $(\mathrm{PF})^{11}$. D-structure is the level at which grammatical functions are expressed in terms of theta-roles. The theta criterion, which states that all theta-roles must be assigned to a noun or NP and all nouns and NPs must be assigned a theta-role, is applicable at this level of representation. D-structure is also the level at which phrase structure rules are applied (Hornstein et al. 2001b:2). Between D-structure and S-structure, movement takes place (Cook and Newson 1996:153). "Move" is one of the rules of the transformational component of GB theory (Hornstein et al. 2001b:4). Specifically, GB theory proposes a rule called "Move $\alpha$ ", according to which anything can be moved anywhere. This rule replaced the (constructionspecific) transformational rules of earlier generative grammar, e.g. wh-movement for question formation, NP movement for passives, etc. S-structure links PF and LF, as it is the level at which the derivation ${ }^{12}$ sends one representation to the PF component, which describes how the words are to be pronounced, and another representation to the LF component, which interprets the meaning of the sentence (Cook and Newson 1996:152,153; Hornstein et al. 2001b:3). Within GB theory, PF and LF are thus interface levels, which provide the grammatical information needed to assign phonetic and semantic interpretations to the 
sentence (Hornstein et al. 2001b:3). These four levels of grammatical representation are illustrated in Figure 2 below, in the traditional "T-model".

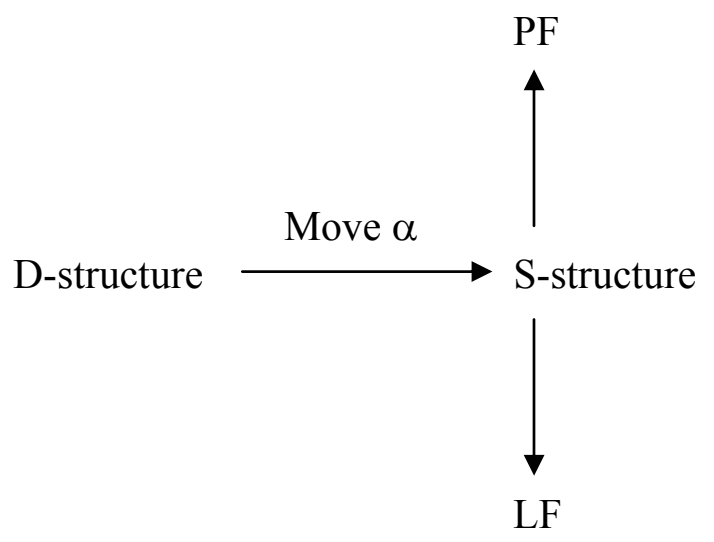

Figure 2. The "T-model" of the GB theory of grammar (from Hornstein et al. 2001b:3)

GB theory, as briefly outlined above, led much fruitful research within the principles and parameters framework. However, more recent influence from the minimalist program (Chomsky 1995a) has led to a re-focused version of the principles and parameters framework, in which the levels of S-structure and D-structure of GB theory are done away with (cf. section 2.3).

\subsection{The minimalist program}

The preference for simplicity that was evident in Chomsky's earliest work (cf. p. 22) currently remains reflected, for example, in the notions of derivational and representational economy. Derivational economy entails that "the derivation should take as few steps as possible", while representational economy entails that "the resulting representations should have as few symbols as possible" (Zwart 1993:13). An example of a principle which expresses representational economy is that of Full Interpretation (FI), according to which only features which actually mean something at a certain level of representation are permitted at that level. Thus, as noted by Zwart (1993:13), uninterpretable material is not allowed at any level of representation. FI is thus an example of a principle which instantiates an economy condition. According to Belletti and Rizzi (2002:32), FI entails, for example, that all features at the level of LF must be semantically interpretable ${ }^{13}$. An example of a principle expressing derivational economy is that of Last Resort, according to which movement takes place only as a last resort, 
as it is a more complex operation than Merge (cf. p. 33), for example (cf. Chomsky 2000:101, 102). There is thus no truly optional syntactic movement, as all movement must be motivated by a certain computational need (Belletti and Rizzi 2002:33) ${ }^{14}$.

Chomsky (2001:1) suggests that the properties of a language L are the result of interaction among three factors. The first of these is the initial state of the language faculty (an instantiation of the principles as proposed above). The second is the primary linguistic data $(\mathrm{PLD})^{15}$, the empirical basis in accordance with which the parameters are set (cf. Figure 3 below). The third, which was not addressed by early work within the principles and parameters framework, comprises general properties of organic systems ${ }^{16}$. Chomsky (2001:2) explains the need to ask "not only what the properties of language are, but why they are that way". The belief is that, once the tension between descriptive and explanatory adequacy is overcome by work within the principles and parameters framework, one can go beyond explanatory adequacy and focus on questions arising from the third factor above, i.e., the nature of the language faculty as an organic system and the role that this plays in determining the properties that natural language systems must have.

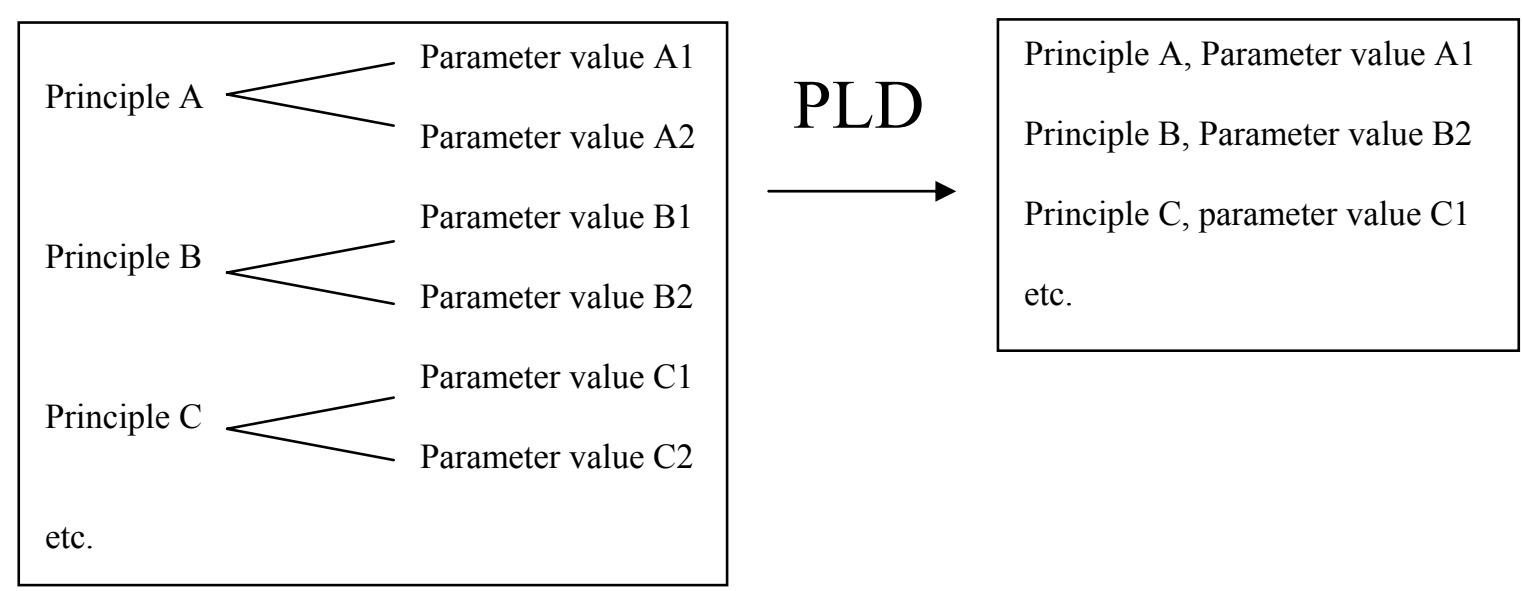

Figure 3 . The role of primary linguistic data in setting parameters

Specifically, Chomsky (1999; 2000; 2002:108) asks the question: Is language optimally designed in terms of the systems with which it must interact? This line of questioning is taken up in the minimalist program, which provides a framework within which questions can be posed regarding the optimality of language design (Chomsky 1997b:1; 1999; 2000). The minimalist program seeks to explore the question of whether language is a perfect system, 
inasmuch as it is a perfect solution to externally imposed constraints (Chomsky 1995a:1). Such externally imposed constraints arise due to the interaction of the language faculty, as a cognitive system, with other performance systems, such as the sensorimotor and conceptual systems. According to Chomsky (1997b:4), the language faculty interacts with these performance systems by means of levels of linguistic representation. The output of the language faculty must satisfy so-called "legibility conditions" imposed by these systems if the systems are to process the output of the language faculty. These legibility conditions comprise what are referred to as "bare output conditions" in the technical literature (Chomsky 1997b:4). An example of such a bare output condition for the sensorimotor performance system is that "a phonetic representation must be linearly ordered" (Lasnik 2002:433), i.e., linearisability must be visible from the structure produced by the syntax. According to Chomsky (2000:112), a strong minimalist thesis is that "language is an optimal solution to legibility conditions". The assumption is then that the language faculty (i) provides only the machinery that is necessary to satisfy the minimal requirements of legibility, and (ii) functions in as simple a way as possible.

The performance systems with which the language faculty must interact, according to Chomsky (1995a:168), are of two general types, namely articulatory-perceptual (A-P) and conceptual-intentional (C-I). These are the systems for which a linguistic expression, the output of the language faculty, must provide instructions. Accordingly, there are assumed to be two interface representations, namely PF (cf. note 11) at the A-P interface and LF (cf. note 5) at the C-I interface (Chomsky 1995a:2), which provide instructions for the A-P and C-I systems, respectively. Chomsky (1995a:169) proposes that these two levels are the only conceptually necessary levels, and so assumes that they can be taken to be the only levels. As Hornstein et al. (2001b:5) note, a fact about natural language is that it pairs form and meaning. As PF and LF comprise the inputs to the A-P and C-I systems, they are conceptually necessary. The GB levels of S-structure and D-structure, in contrast, are theory-internal levels, being empirically motivated rather than conceptually motivated. Research within minimalist syntax (cf. section 3.1) has suggested that the empirical burden of these two levels of representation can be more adequately carried by mechanisms operating between the lexicon and PF and LF (cf. Hornstein et al. 2001b:5-36). Thus, the conceptually unnecessary levels of D- and S-structure are eliminated in the spirit of economy, according to which two 
levels of representation are better than four. The assumption of PF and LF as the only levels of representation, based on the notion of 'virtual conceptual necessity', forms an important part of the minimalist program. Another assumption central to the minimalist program is that the language faculty consists of two components, namely a lexicon and a computational system (Chomsky 1995a:168). A linguistic expression is derived by the selection of an array of lexical items and a computation that derives the PF and LF interface representations (cf. section 3.1).

The legibility conditions mentioned above, then, apply at the interfaces between the language faculty and the A-P system, on the one hand, and between language faculty and the C-I system, on the other. Thus, the interface legibility conditions are satisfied by a principle such as that of Full Interpretation (cf. p. 27), whereby all features in a representation must be interpretable at the relevant interface, i.e., PF features interpretable by (i.e., legible to) the A-P system, and LF features interpretable by (i.e., legible to) the C-I system. Chomsky (1995a:171) further proposes that a linguistic expression is an optimal realisation of these interface conditions, where optimality is determined by the economy conditions of UG, i.e., conditions which ensure computational simplicity and least effort ${ }^{17}$.

The above-mentioned strong minimalist thesis holds that all states of the language faculty (initial or attained) must satisfy the interface legibility conditions, and so puts aside the distinction between descriptive adequacy (for a theory of an attained state of the language faculty) and explanatory adequacy (for a theory of the initial state) (Chomsky 2002:131). This assumption that all states of the language faculty satisfy legibility conditions in an optimal way is central to questions posed by the minimalist program.

The task of the minimalist program, according to Chomsky (2001:3), is to examine the devices employed to characterise language and determine the extent to which such devices can be eliminated in favour of a principled account in terms of general conditions of computational efficiency and interface conditions that the organ - in this case, the language faculty - must satisfy in order to function. The goal of research within the minimalist program is to determine which aspects of the structure and use of language are specific to the language faculty. 
It must be emphasised that the minimalist program is a research program, and not a theory. The minimalist program, as has been mentioned, provides the framework for research that aims to answer the questions posed above with regard to the optimality of language design. As Chomsky notes (cf. the interview in Cheng and Sybesma 1995:32), one cannot speak of a minimalist approach to something, as "there is no specific minimalist approach. There is a set of minimalist questions", and in this sense the minimalist program is a "set of questions that guide inquiry".

Research carried out from such a minimalist perspective, however, has led to the development of a number of theories to account for various syntactic phenomena. These theories can collectively be referred to as "minimalist syntax". Thus, within minimalist syntax, there may be a theory of verb movement, a theory of feature checking, etc. Indeed, there may be more than one theory for a specific phenomenon, in which case the minimalist criteria of simplicity, economy, and elegance may be useful in selecting the "best" theoretical account. Hornstein et al. (2001b:4) posit that it is one of the tasks of the minimalist program to "find ways of understanding what constitutes a more or less natural ... or more or less elegant syntactic account". It is thus not clear at present precisely what criteria such as elegance and naturalness entail, nor how theories are to be evaluated in terms of such criteria.

In summary, the development of the field of generative syntax can be represented as in Figure 4 overleaf. 


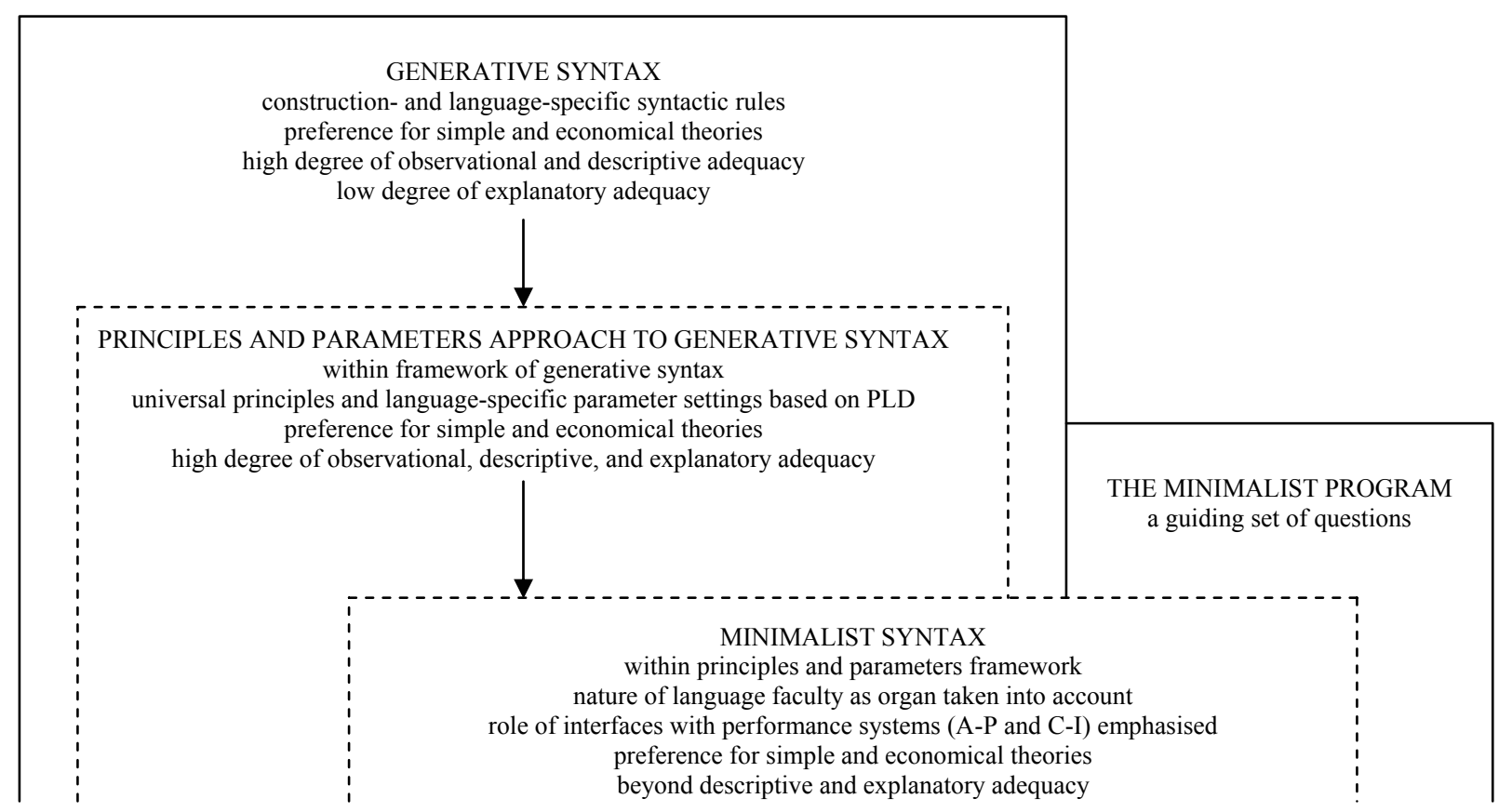

Figure 4. Diagrammatic representation of the development of the field of generative syntax

In what follows, attention will be focused on particular aspects of current syntactic theory which may inform the clinical processes of assessment, classification, and remediation. The discussion does not provide a comprehensive overview of generative or minimalist (or any other kind of) syntax. The aim is merely to set out some of the central aspects of current syntactic theory, and to illustrate how the SLP may apply such theoretical knowledge in clinical practice. The interested reader is referred to the paper by Leonard and Loeb (1988), which provides an overview of GB theory and discusses some applications in clinical practice. In addition, Shapiro (2000) provides an introduction to syntax within a principles and parameters framework for SLPs.

\section{ASPECTS OF SYNTAX RELEVANT TO CLINICAL PRACTICE}

\subsection{Some assumptions and devices of minimalist syntax}

A brief sketch of some assumptions and devices of minimalist syntax will provide the background necessary to follow the discussion of certain aspects of syntax relevant to SLPs which is undertaken below. As noted in section 2.3, Chomsky (1995a:168) proposes that the 
language faculty consists of two components, namely a lexicon and a computational system for human language $\left(\mathrm{C}_{\mathrm{HL}}\right)$. The lexicon specifies the lexical items with their idiosyncratic features. An example is the verb pour in English, which will be specified for features such as [tense], allowing for e.g. present tense pour and past tense poured, and [person], allowing for e.g. third person singular pours. $\mathrm{C}_{\mathrm{HL}}$ derives a linguistic expression, also known as a structural description $(\mathrm{SD})^{18}$, on the basis of a selection of lexical items, a numeration $\mathrm{N}$ (Chomsky 1995a:169). The derivation proceeds as the operation Merge strings the lexical items together in binary fashion, and the operation Move carries out the necessary movement of lexical items (cf. section 3.4). This derivational process is illustrated in Figure 5 below.

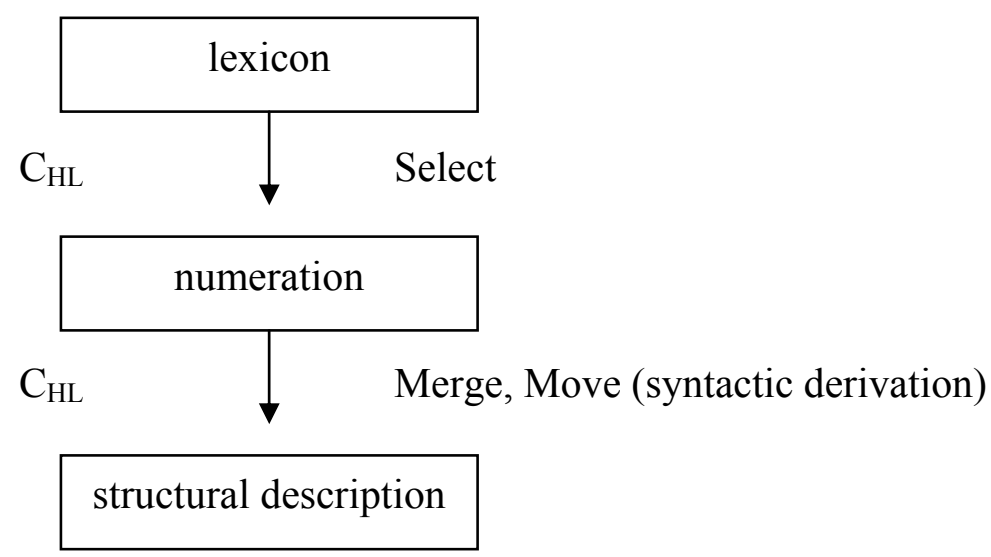

Figure 5. The derivation of a structural description according to minimalist syntax

$\mathrm{C}_{\mathrm{HL}}$ consists of two parts, namely the PF component, relevant to PF (at the A-P interface), and the LF component, relevant to LF (at the C-I interface) (Chomsky 1995a:169). A linguistic expression of $\mathrm{L}$ is then a pair $(\pi, \lambda)$, where $\pi$ is a PF representation and $\lambda$ an LF representation (Chomsky 1995b:390). Chomsky (1995b:394) posits that $\pi$ and $\lambda$ are "differently constituted", and elements interpretable at the PF interface are not interpretable at the LF interface, and vice versa. The computation must split, at some point, into a part forming $\pi$ and a part forming $\lambda$. This point is known as "Spell-Out" (Chomsky 1995b:394). At Spell-Out, the elements relevant only to PF are stripped away and mapped onto $\pi$, while the remainder continue in the computation to LF to be mapped onto $\lambda$. A distinction is made between the socalled "overt syntactic component", operating before Spell-Out, and the "covert syntactic component", operating after Spell-Out (cf. Figure 6 overleaf). Thus, for instance, movement 
that occurs in overt syntax will be visible (spelled out) at PF, while movement that occurs in covert syntax will not be reflected in the structure that is produced.

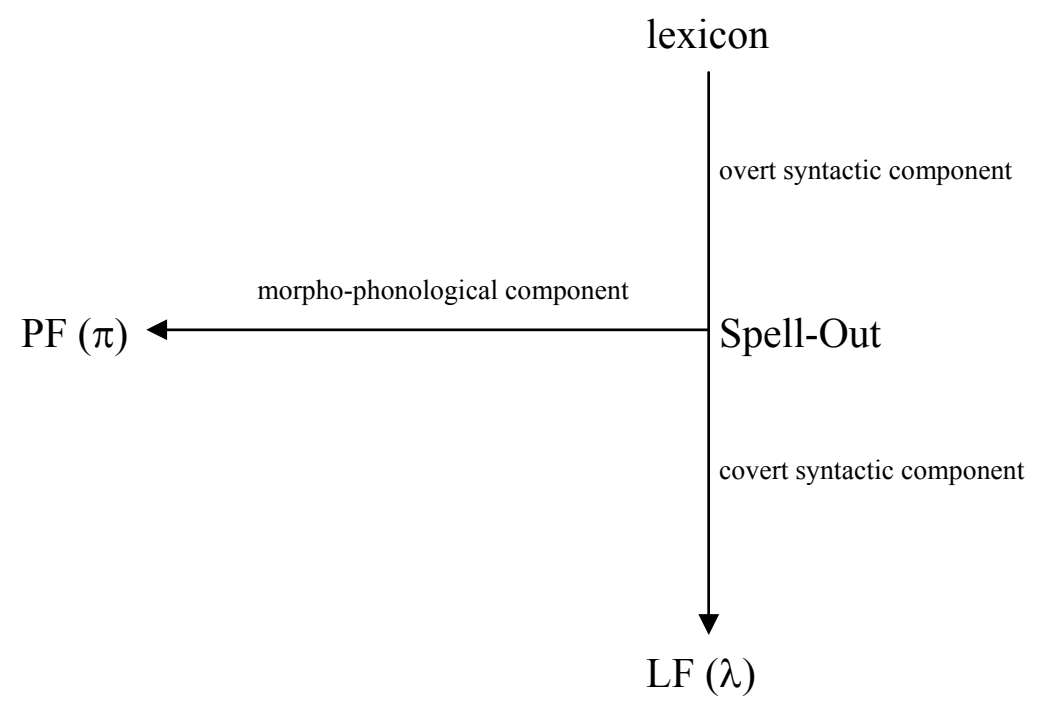

Figure 6. The overt and covert components of $\mathrm{C}_{\mathrm{HL}}$

On the basis of universal and invariant principles and fixed parameter settings, then, a language $\mathrm{L}$ determines an infinite set of SDs, each a $(\pi, \lambda)$ pair. A derivation is said to "converge" if it produces a legitimate SD, and to "crash" if it does not (Chomsky 1995a:171). A derivation can converge or crash at either PF or LF, and must converge at both PF and LF if it is to converge at all (Chomsky 1995a:171). The above-mentioned legitimacy of an SD is determined by the principle of Full Interpretation (cf. p. 27), whereby uninterpretable features associated with certain categories must be "checked" (cf. section 3.3 on feature checking). Movement, discussed in section 3.4, is the mechanism whereby lexical items move, allowing such feature checking to take place.

This brief introduction to minimalist syntax serves to provide the SLP with a background to current syntactic theory within the minimalist framework. In the following sections, three aspects will be discussed in more depth, namely the distinction between lexical and functional categories, feature checking, and movement. 


\subsection{Lexical and functional categories}

The term "(grammatical) categories" is used to refer to what may traditionally be known as "parts of speech". Specifically, a distinction is made between lexical categories (such as nouns, verbs and adjectives) and functional categories (such as auxiliary verbs like will and should and complementisers like that and if). These grammatical categories define sets of words which share grammatical properties (Radford 1997a:29). Every word in a language belongs to a grammatical category, and every competent speaker-hearer unconsciously uses his knowledge of the properties of such grammatical categories in producing and comprehending language. Categories, for example, form the basis of the structure dependence principle $^{19}$, a fundamental principle of UG, according to which all grammatical operations are structure-dependent, thus sensitive to the grammatical properties of every word in the sentence (Radford 1997a:12, 15).

One type of evidence for the existence of distinct grammatical categories, each defining a set of words which share grammatical features, comes from morphology. For example, nouns like cat and dog in English and muis ("mouse") and blaar ("leaf") in Afrikaans can be pluralised by the addition of the inflectional morphemes $-s$ and -e, respectively, to give cats, dogs, muise ("mice") and blare ("leaves"). Verbs like translate, on the other hand, cannot undergo such pluralisation, but can be inflected for tense, e.g. with past tense -ed in translated. Furthermore, derivational morphemes, by which words are derived from other words, can only be attached to words of certain categories, e.g. English un- and Afrikaans on- in uncomfortable and ongelukkig ("sad") from the adjectives comfortable and gelukkig ("happy"). Other examples of derivational processes that are category-specific include the formation of an adverb from an adjective in English, e.g. beautifully from beautiful, and the formation of an adjective from a verb in Afrikaans, e.g. aanvaarbaar ("acceptable") from aanvaar ("accept"). It can be seen that it would not be possible to give a systematic account of the inflectional and derivational systems of English and Afrikaans without positing that words belong to grammatical categories, and that certain types of inflectional and derivational morphemes can attach only to words of certain grammatical categories (Radford 1997b:39). 
For syntactic evidence for the existence of grammatical categories, one can turn to the distribution of categories, where it is evident that different categories of words can occupy different positions within sentences (Radford 1997a:32). For example, only a noun - and not an adjective, adverb, or verb - may follow a determiner like $a$ in English or die ("the") in Afrikaans, as in There was a girl/car/*beautiful/*sit and Gee my die pop/boek/*sag/*hardloop ("Give me the doll/book/*soft/*run"). It is clear, too, that only certain kinds of words can be modified by certain others, hence the traditional distinction between adverbs and adjectives in English, as in A pretty/clever girl, but not *A prettily/cleverly girl. Prepositions provide another example of distributional restrictions, where only a noun (phrase) can follow a preposition, as in Hy sit op die bank/aan tafel ("He sits on the couch/at the table"), but not *Hy sit op praat/aan beeldskoon ("He sits on talk/at beautiful").

From the perspective of an SLP, Shapiro (2000:5) mentions the implications of the above distinction between various grammatical categories for language acquisition. During the process of language acquisition, the child merely has to learn that "nouns can be pluralised" and "verbs can be given past tense", and how this is done in the language concerned, rather than learning the various forms of each individual word ${ }^{20}$. These generalisations, then, allow the grammar of a language to be represented economically in the mind of the speaker-hearer (cf. the economy considerations discussed in section 2).

It is clear from the above that one may assign the words of a language to different grammatical categories. The categories referred to above (nouns, verbs, adjectives, adverbs, and prepositions ${ }^{21}$ ) are lexical categories, in that they comprise words with idiosyncratic descriptive content, often called "content words" (Radford 1997a:37). Functional categories, on the other hand, are elements which carry information about the grammatical properties or functions of expressions within the sentence (like number, person, gender, and case), also known as "function words" (Radford 1997b:45). A brief overview of certain functional categories, namely determiners, auxiliary verbs, the infinitival to, and complementisers, will be given below.

A determiner (D) can be said to determine the referential or quantificational properties of the noun (phrase) it precedes (Radford 1997b:45), as in She ate the cake with a fork and Ek 
verkies hierdie jas bo jou een ("I prefer this coat to your one"). One may ask why determiners cannot be regarded as adjectives, and thus as a lexical category, as adjectives and determiners appear to modify nouns and NPs in a similar way. Besides the lack of lexical content of many determiners (e.g. $a$, the), it is clear that determiners and adjectives also differ in their distributional properties (Radford 1997b:46, 47). For example, a "list" of adjectives can be used to modify a noun (phrase), whereas determiners cannot be used in this way, e.g. The tall, tanned, lithe, beautiful girl but not *These the all girls. Furthermore, a determiner can precede an adjective or adjectives, as in Die nuwe swart perd ("The new black horse"), but an adjective or adjectives may not precede a determiner, as in *Nuwe swart die perd ("New black the horse"). It is clear, then, that determiners comprise a functional category of their own.

A second functional category is that of auxiliary verbs (AUX), a functional category associated with verbs, in the same way that the functional category of determiners discussed above is associated with nouns. Radford (1997b:50) notes that an AUX differs from a verb in that an AUX takes a verb as its complement, and functions to mark grammatical properties associated with the verb, such as tense, as in The man will go and The man had gone. A further syntactic difference between AUX and verbs, mentioned by Radford (1997b:50, 51), concerns the fact that AUX may undergo so-called "inversion" in question formation in some languages, such as English, as in the question Will you go? from the statement You will go. Main verbs in English generally require what is known as "do-support" for questionformation, as in Do you want to go? rather than *Want you to go? Finally, according to Radford (1997b:51), AUX can generally be negated by a following not in English, usually contractible to $n^{\prime} t$, as in You should not/shouldn't go. Main verbs in English, on the other hand, require the above-mentioned do-support for negation, as in I do not/don't see, rather than *I see not/seen't. These examples illustrate that there are clear differences between the lexical category of verbs and the functional category of AUX.

A third functional category is the infinitival (infinitive particle) to, named for the fact that it only allows a complement with a verb in the infinitive form, i.e., in the uninflected base form (Radford 1997a:46). This can be seen in sentences like I want to go and We would like to eat now. The infinitival to is not to be confused with the preposition to, which has some kind of 
lexical content, as in I walked over to the man, where to means something like "as far as" (Radford 1997a:46). The infinitival to, in contrast, serves a grammatical function only, similar to that of AUX discussed above. Furthermore, infinitival to shares distributional properties with at least some kinds of AUX. Consider, for example, It is important for me to go and It is important that I should go, where to and should both require a complement of a verb in its infinitive form. These similarities between AUX and infinitival to lead to their being regarded as a single category, known as "Inflection", or INFL, or just I (Radford 1997a:48).

The final functional category to be discussed is that of complementiser (COMP/C), which includes items that introduce complement clauses, as in Ek weet dat jy van hierdie motor hou ("I know that you like this car") and Ek wonder of hy daardie meisie ken ("I wonder if he knows that girl"). COMP can be seen as a functional category as words in this category carry grammatical information only. For example, they are either finite or infinite. This can be illustrated by the fact that a finite COMP like that or if can only introduce a complement clause containing a finite verb (marked for tense), as in I know that you are tired and She did not know if he had gone, whereas an infinitival complementiser like for can only introduce a complement clause containing an infinitival to, as in He would like for me to pass the test (Radford 1997a:50).

The above discussion of lexical and functional categories demonstrates why linguists posit that these categories define sets of expressions which share grammatical properties. Because, as has been mentioned, every competent speaker-hearer unconsciously uses his knowledge of the properties of such grammatical categories in producing and comprehending language, a thorough understanding of these categories is of great importance to the SLP. Such knowledge can be applied in clinical practice with language disordered patients who exhibit deficits in one or more of these grammatical categories. With regard to syntactic structure, it is important to note that the distinction between lexical and functional categories leads to a distinction between lexical and functional heads, which are the heads of lexical and functional projections, respectively. According to Radford (1997a:269), "a projection is the expansion of a head". For example, the NP studente van Stellenbosch ("students from Stellenbosch") is a projection of its head, the noun studente ("students"). 


\subsection{Feature checking}

Within minimalist syntax, the grammar is feature-driven, in that movement (cf. section 3.4) of lexical items occurs in order that feature checking can take place. Feature checking, in turn, is "triggered by the need to eliminate uninterpretable features from the computation" (Hornstein, Nunes, and Grohmann 2003:3). It is assumed that lexical items consist of bundles of features, namely phonological, semantic, and formal (syntactic) features. Radford (1997a:67) explains how formal features describe the grammatical properties of words, proposing specifically that a word has three sets of formal features, namely head features, complement features, and specifier $^{22}$ features. Head features describe the intrinsic grammatical properties of the word. For example, the AUX is in He is running the show carries the head feature [+present], which indicates that it is a present tense form. Complement features describe the kind of complement a word takes. For example, is in the sentence above has the feature [+ing], as it takes a complement containing a head verb that has a participial inflection -ing. Specifier features describe the kind of specifier a word can have. For example, is has a case feature, whereby it takes a nominative subject as its specifier, like he, and not an accusative subject like him. Furthermore, is has agreement ${ }^{23}$ features for person and number, whereby it takes a third person singular subject like he or she, and not, for example, I (first person singular) or they (third person plural).

As noted in section 3.1, phonological features are interpretable at PF, but not at LF, while semantic features are interpretable at LF, but not at PF (cf. Chomsky 1995b:394). At the point of Spell-Out, the derivation splits into two, the phonological features being sent to PF and the semantic features to LF. It may be that certain formal features are required for the morphophonological component (cf. Figure 4), but these formal features have to be deleted after fulfilling their function, i.e., after playing their role in allowing the derivation to converge at PF. An illustrative example is the formal feature [+plural] in karre ("cars"), which is associated with a phonological feature bundle, the phoneme /a/. Once these formal and phonological features have been manipulated by the morpho-phonological component, only the phonological features proceed to $\mathrm{PF}$, in order that the derivation does not crash, as the formal feature [+plural] is not interpretable at PF (cf. Hornstein et al. 2003:4). Although the issue is more complex in the case of the legibility of formal features at LF (cf. Hornstein et al. 
2003:4, 5), it appears that these are not interpretable at LF either, the information conveyed by formal features in this case being conveyed adequately by semantic features alone.

The question arises as to why lexical items possess uninterpretable features, as this phenomenon is in contrast to the optimality and economy which the minimalist program aims to posit as an inherent property of the language faculty. In the absence of a clear answer to this question, Hornstein et al. (2003:5) suggest that movement, discussed in section 3.4 below, is the mechanism whereby these uninterpretable features may be eliminated. Thus, movement is the optimal solution to the problem of uninterpretable features, the existence of which is allowed to remain a mystery. Movement, in turn, must comply with the economy condition of Last Resort, according to which movement is only allowed if it leads to the elimination of uninterpretable features (Hornstein et al. 2003:5). Note that, upon the matching of features, only the uninterpretable feature is eliminated. The interpretable feature continues in the computation, and may even be used in subsequent feature checking operations (Hornstein et al. 2003:6).

\subsection{Movement}

Within GB theory, the precursor of minimalist syntax within the principles and parameters framework, movement was proposed as an operation that takes place to generate the Sstructure of a sentence from the underlying D-structure (cf. Move- $\alpha$ on p. 26) (Cook and Newson 1996:45, 46). For example, the D-structure of the question Waar is die geld? ("Where is the money?") would essentially be Die geld is waar? ("The money is where?"). Wh-movement of waar ("where") and AUX-movement of is ("is") were proposed to lead to the derivation of the S-structure from the D-structure. The S-structure (within the earlier GB framework), in which the original positions of the elements have to be indicated if the semantic interpretation of the sentence is to be correct, is interpreted (within the more recent minimalist framework) by the PF and LF components, which yield the phonetic and semantic representations, respectively (Cook and Newson 1996:46, 47). It is proposed that a moved element leaves behind a trace in its original position, specifically, a co-indexed trace, as in

Waar $_{i}$ is $s_{j}$ die geld $t_{j} t_{i}$ ?, allowing the LF representation to be correctly interpreted ${ }^{24}$. In minimalist syntax, the category-specific movement rules of earlier theories of generative 
grammar, as well as the general rule Move- $\alpha$, are replaced by Move (cf. p. 33). Move in minimalist syntax essentially means "move nothing nowhere", in terms of which a lexical item may only move as a last resort (cf. p.40), for the purposes of feature checking. There is thus no optionality of movement in minimalist syntax.

Before moving on to a discussion of certain types of movement, it is important to point out that movement theory is in no way linked to processing accounts of language production such as those of Garrett (1980, 1988), Dell and Reich (1981), Dell and O'Seaghda (1992), and Levelt (1992). There is no sense in which one lexical item is moved first, temporally speaking, and then a different item is moved, or an item is moved first to one position and later to another. The theory of syntax in the principles and parameters framework is a theory of the I-language ${ }^{25}$, in which process (in terms of time and direction of movement, for example) does not feature (Cook and Newson 1996:190). Rather, movement is a way of expressing the relationship between a D-structure and an S-structure, or between the structure of the initial numeration and the structure of the LF representation. The concept of a chain is helpful here, where the chain is a record of the links that exist between one representation and another (Cook and Newson 1996:190), such as the co-indexed chain of traces in Waar $_{i}$ is $_{j}$ die geld $t_{j} t_{i}$ ? above. In the remainder of this section, two types of movement will be discussed, namely head movement and operator movement.

Head movement, or head-to-head movement, entails movement from one head position to another. An example is AUX movement, i.e., the movement of AUX to a position preceding the subject in inversion structures such as yes-no questions in English. Radford (1997a:106) compares a yes-no question in English, like Will he eat the food?, to a complementiser phrase (CP), like If he can eat the food, where the AUX will in the first sentence occupies the same position as the complementiser if in the second sentence. This position is $\mathrm{C}$, the head of $\mathrm{CP}$, as can be seen in the tree diagrams in Figure 7 overleaf. 

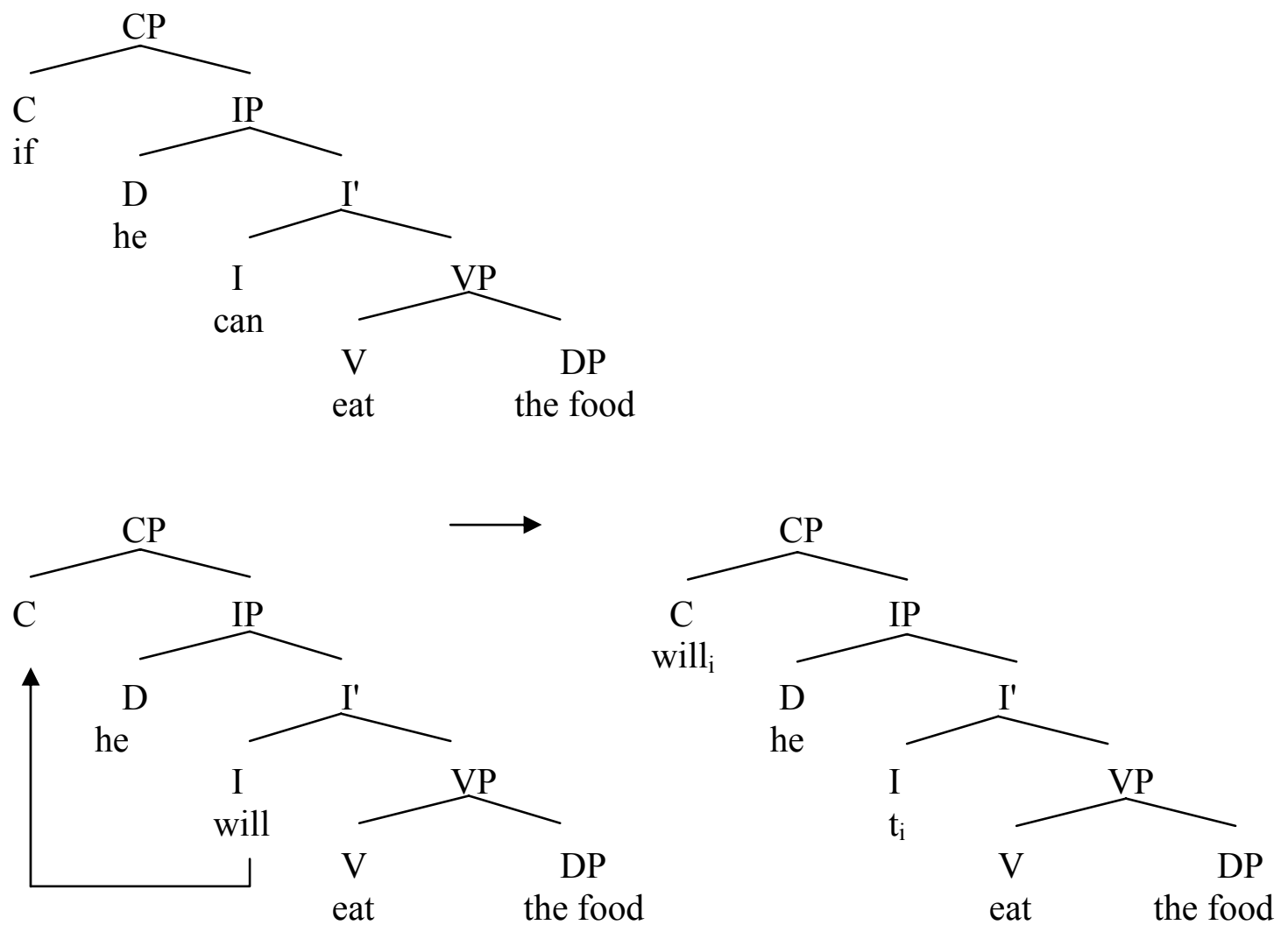

Figure 7. Tree diagrams depicting AUX movement

As Radford (1997a:108) notes, the question arises as to why AUX should undergo such head movement, i.e., what makes the head movement analysis here plausible. Bear in mind that movement must be motivated by a certain computational need (cf. note 14). A proposal made by Chomsky (1995a) entails that COMP in an interrogative CP is a "strong" head and therefore must be filled. The strong COMP has the power to attract the AUX from the I position. A brief explanation of category "strength" is required here. Within minimalist syntax, there is an assumption that some categories and features are strong and others weak. Radford (1997a:109, 110) provides an analysis of auxiliariless yes-no questions in English, which require do-insertion, as an illustration of strong and weak categories. Consider, for example, the tree diagrams in Figure 8 below of the statement You like ice cream, and the question Do you like ice cream?, where a "dummy" (or expletive) do is inserted. 

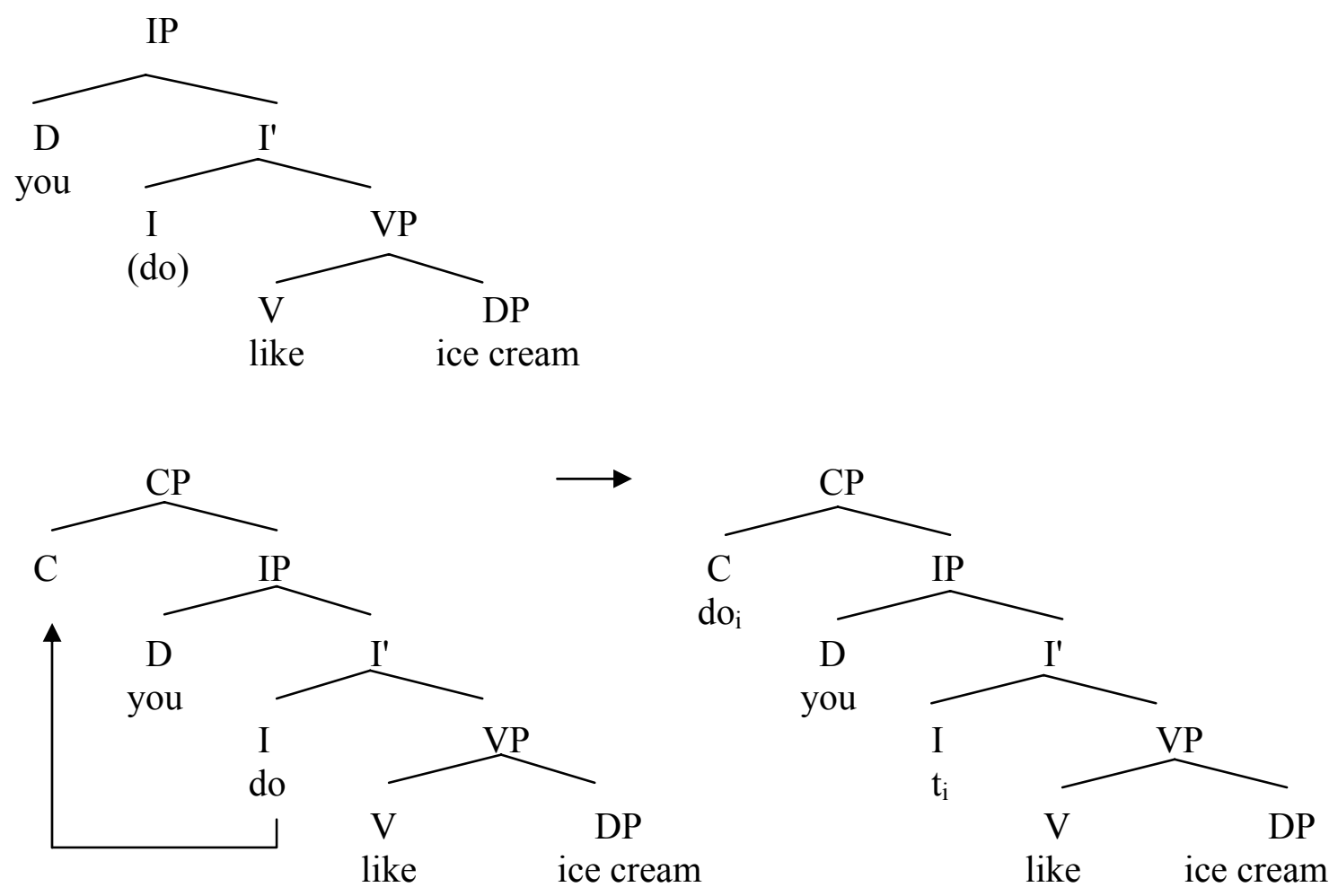

Figure 8 . Tree diagrams depicting do-insertion

It is proposed that the interrogative COMP is strong, and so must be filled (with do, generated in the I position), while I is weak, and so need not be filled, as is clear from You (do) like ice cream, where the do is not necessary. Note that there is no implication of optionality here: the filling of I by do is not optional. Indeed, do insertion in such a statement implies a particular (different) meaning. This lack of optionality relates to the economy considerations mentioned in section 2 .

In the more recent terms of feature interpretability, COMP may be proposed to have an uninterpretable question/q-feature which must be eliminated by the movement into that position of a lexical item with an interpretable q-feature, namely will and do in the first and second examples above, respectively.

The second type of movement to be discussed is operator movement, i.e., the movement of an operator or operator expression. An example of an operator is the interrogative operator which in Which eggs can we fry?, where which eggs is an operator expression. Such an interrogative operator triggers AUX inversion in English (Radford 1997b:267). In this case of operator 
movement, the complement of the verb (V) in a verb phrase (VP) moves to the Spec of CP position. Consider the tree diagram of the question Which eggs can we fry? in Figure 9 below.

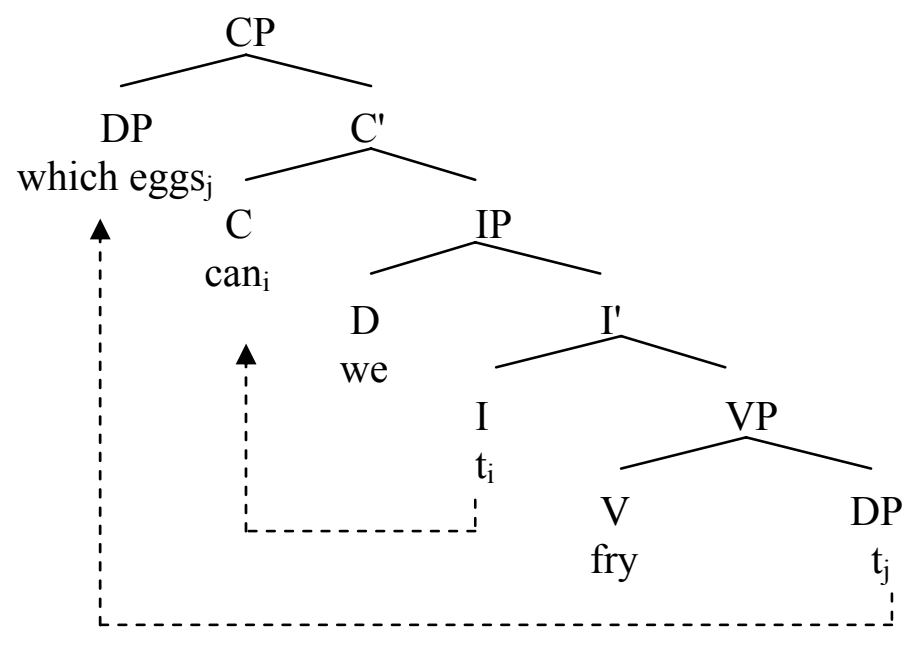

Figure 9. Tree diagram depicting operator movement

From this tree diagram, it is clear that AUX movement (discussed above) is instantiated in the movement of can from I to the head $\mathrm{C}$ position of $\mathrm{CP}\left(\mathrm{C}^{\prime}\right.$ in the tree diagram). The operator expression which eggs, then, moves from its base position as complement of the $\mathrm{V}$ fry in the VP to the position of Spec CP. An explanation for why the interrogative operator expression which eggs moves to the Spec CP position is offered by Radford (1997a:135). Again, it is proposed that the head COMP in questions carries an uninterpretable interrogative specifier feature, which must be checked so as to be eliminated. It is further proposed that an interrogative operator like which carries an interpretable interrogative head feature. On this analysis, the interrogative operator moves to Spec CP to check the uninterpretable interrogative feature of COMP (Radford 1997a:135).

This brief discussion of two types of movement as accounted for within minimalist syntax should provide the SLP with the background necessary to follow discussions of the clinical application of theories of movement. The clinical application of some of the aspects of theoretical syntax discussed above, specifically in the areas of specific language impairment (SLI) and agrammatism, forms the focus of the following section. 


\section{SOME CLINICAL APPLICATIONS OF SYNTACTIC THEORY}

\subsection{Specific language impairment}

A basic understanding of syntax is essential for SLPs who work with children with SLI. The first application of the SLP's syntactic knowledge to be discussed here involves the formal description of the syntactic abilities of the child with SLI. Such a description plays a central role in evaluation and remediation, its efficacy in this role being directly proportional to its level of linguistic detail. Van der Lely (2003:125), for example, describes the syntactic features of SLI, noting that children with SLI often present with (i) deficits in tense and agreement marking, (ii) problems with thematic role assignment (cf. note 10), (iii) difficulties with structural relations in general, and (iv) variation in performance with the same syntactic structure. SLPs can apply their understanding of syntax during evaluation, enabling them to obtain the maximum amount of information that should be incorporated into a description of the syntactic abilities of the child with SLI.

Such application of the SLP's understanding of syntax is discussed by Leonard (1998:56), who notes that children with SLI may present with difficulties in the areas of both syntactic structure and grammatical morphology. Syntactic structure has to do with the distribution of elements in the sentence, and the relationships between these elements, thus with word order and movement operations. Grammatical morphology involves the so-called "bound morphemes", like the plural -e in eende ("ducks") and the past tense -ed in washed, as well as the functional categories such as AUX and COMP discussed in section 3.2. Leonard (1998:56) notes, however, that the division between syntactic structure and grammatical morphology is "somewhat artificial", and that problems with one of these areas will necessarily have effects on the other. For example, a problem with syntactic structure may make it difficult for the child to correctly construct a passive sentence like He was kicked by her from the active sentence She kicked him, where grammatical morphology also plays a role in the form of the pronouns (she - her and him - he), the bound morpheme -ed, and the AUX was. 
A second reason for positing that the SLP requires an understanding of syntax is in order to follow research in the area of SLI, the results of which have potential implications for the clinical management of children with SLI. For example, in Leonard's (1995) study of the use of functional categories and related grammatical elements by children with SLI, it was noted that these children tended to produce AUX in its base-generated declarative sentence position in questions (i.e., its position at Merge), rather than in its inverted position (i.e., its position after Move) (cf. section 3.4), as in *What we can make?, rather than What can we make?. On the basis of such findings, SLPs can apply their understanding of what syntactic movement operations like AUX inversion entail in order to (i) infer generalisations regarding other movement operations that may be similarly affected, (ii) make an accurate diagnosis of the nature of the problem underlying surface forms like *What we can make?, and (iii) devise therapy materials to target AUX inversion, which have the potential to aid the child in mastering other movement operations too, thereby enhancing the efficacy of the therapy through generalisation.

A third manner in which SLPs may apply their knowledge of syntax is in assessing the theoretical merit of the various proposals made to account for SLI. Southwood (2003) discusses a number of such proposed accounts. One proposal to account for SLI is that of Loeb and Leonard (1991:346), who suggest that SLI children have problems with functional categories due to the absence of an INFL node in the syntactic tree, which leads to the absence of subject-verb agreement and subject case marking, as agreement and case marking are dependent on INFL features. A second account of SLI, offered by Van der Lely (2003:126), is the Representational Deficit for Dependent Relations (RDDR) Hypothesis. According to the RDDR Hypothesis, the core problem in SLI is the inability to establish dependent syntactic relations, which leads to difficulties with movement that is dependent on such syntactic relations. Thus, movement that is obligatory in normal language is optional in the language of persons with SLI. A third account for SLI is based on Wexler's (1994:311312) proposal of an optional infinitive stage in children with normal language development, during which finite and non-finite forms of the verb are in free variation. During this stage, non-SLI children do not obligatorily mark tense in main clauses, although they are aware of the grammatical properties of finiteness (Rice, Wexler, and Cleave 1995:851). To account for SLI, Rice, Wexler, and Cleave (1995:852-853) propose an extended optional infinitive stage, 
whereby the optional infinitive stage described above is prolonged in children with SLI. From this brief overview of a selection of proposed accounts for SLI, it should be clear that SLPs must have a good grasp of current syntactic theory if they are to understand the accounts given for the phenomena observed in SLI, and to decide which account may be the most plausible in light of their own clinical experience.

A fourth and final manner in which SLPs can apply their understanding of syntax to SLI is in the identification of clinical markers of SLI. Conti-Ramsden and Hesketh (2003:251) mention the importance of identifying certain clinical markers of SLI, which can be used to distinguish between children with SLI and those who are younger but are developing language normally. Rice and Wexler (1996:1239) also note the necessity of such a clinical marker, "a linguistic form or principle that can be shown to be characteristic of children with SLI". Specifically, Rice and Wexler (1996) investigated grammatical tense as a potential clinical marker of SLI in English, basing their study on the above-mentioned proposal of an extended optional infinitive stage to account for SLI. Rice and Wexler's (1996) study targeted a certain set of morphemes which mark tense in English, namely third person singular -s, regular past -ed, and forms of be and do. The study revealed lower levels of accuracy for the target morphemes in the language of 4 to 5 year old SLI children than in that of non-SLI controls, but no such lack of accuracy in non-tense marking morphemes. Thus, the results of the study indicate that a set of morphemes which mark tense may indeed constitute a clinical marker of SLI in English (Rice and Wexler 1996:1250). It may be that there are other clinical markers of SLI in English and/or in other languages, and the SLP requires a sound understanding of syntax in order to investigate the possibilities further. The identification of such clinical markers has an important role to play in the SLP's characterisation of the nature of the grammatical limitations of SLI children, as well as providing a means for early identification of SLI children (Rice and Wexler 1996:1251).

As De Jong (2003:152) notes, linguistically oriented research into SLI is aimed at a characterisation of the symptoms of SLI within an agreed-upon linguistic framework, thereby improving the specificity of the diagnosis and therapy aims. In this regard, it must be noted that any change in the linguistic framework being applied (e.g. a change in theory from language-specific, construction-specific transformational rules to a general operation like 
Move) will have an effect on an explanatory account of the linguistic behaviour of SLI children. It should also be noted that the plausibility of such explanatory accounts may be challenged by new data from languages not previously studied (De Jong 2003:153). It is thus important for SLPs to apply their own knowledge of syntax, their knowledge of the language(s) they speak, as well as their own experience with SLI children, in determining the applicability of a particular theoretical account to the clinical situation.

\subsection{Agrammatism}

Knowledge of syntax has an important role to play in the grammatical characterisation of aphasic language, specifically that of agrammatism. Edwards, Garman, and Knott (1993:217) note that "clinicians are now seeking to achieve both a better understanding of the language processes that might explain aphasic behaviour and to produce coherent and comprehensive descriptions of aphasic language". SLPs can apply their knowledge of syntax in developing their understanding of the syntactic processes that may underlie the symptoms of agrammatism, as well as in the description of agrammatism within a linguistic framework shared by other SLPs, and one which reflects current trends within syntactic theory.

Much recent research on the linguistic aspects of aphasia has focused on the difficulties agrammatic speakers commonly exhibit with functional categories, as it has long been thought that agrammatism constitutes a language deficit implicating all functional morphemes. More specifically, studies have focused on verb inflection (cf. Friedmann and Grodzinsky 1997; Friedmann 2001; Arabatzi and Edwards 2002). Friedmann and Grodzinsky (1997), for example, studied a Hebrew-speaking agrammatic speaker who exhibited a selective impairment of tense inflection, in the presence of intact agreement (number, gender, and person) inflection. Friedmann and Grodzinsky (1997:411) based their account of this agrammatic phenomenon (namely the dissociation between different types of verb inflection) on the split inflection hypothesis offered by Pollock $(1989 ; 1997)$. Prior to Pollock's (1989) split INFL hypothesis, it was assumed that features of both tense and agreement were contained within the IP. However, in order to allow for certain cross-linguistic data (among other things), Pollock (1989) suggested that the INFL node should be split into two separate 
projections, namely tense (T) and agreement (Agr), where T takes AgrP as its complement and Agr takes the VP as its complement, as in the tree diagram in Figure 10 below.

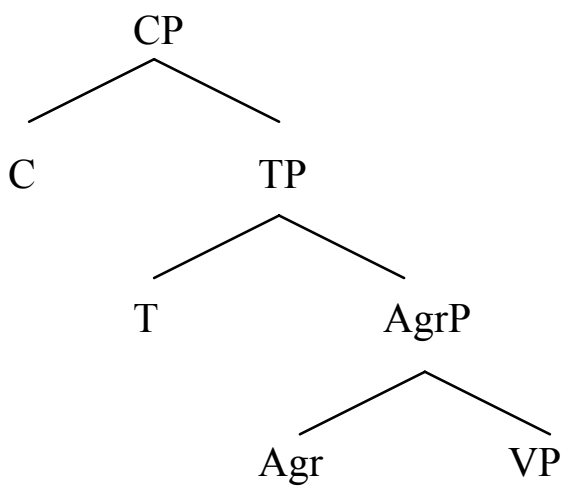

Figure 10. Tree diagram depicting the split-INFL hypothesis

On the basis of the above-mentioned split-INFL hypothesis, Friedmann and Grodzinsky (1997:414) proposed the Tree Pruning Hypothesis (TPH) in order to account for the dissociation between tense and agreement inflection in the agrammatic subject they studied ${ }^{26}$. According to the TPH, there is underspecification of $\mathrm{T}$ in agrammatic production, and this underspecified node cannot project any higher. In other words, the deficit in agrammatism impairs the T node and every node in the syntactic tree above T (Friedmann and Grodzinsky 1997:415), explaining the selective impairment of T while Agr remained intact, and also explaining the subject's difficulties with tense, copula forms, complementisers, and wh-words, these being affected by virtue of their position under $\mathrm{CP}$, which is also higher in the tree than T.

The above analysis of the symptoms of agrammatism in terms of a deficit in the syntactic tree was further investigated up by Friedmann (2001). In this investigation of fourteen agrammatic subjects and the available literature, data were found to support the notion of a single underlying deficit, namely the inaccessibility of higher nodes in the syntactic tree, affecting structures related to these higher nodes, while leaving structures related to lower nodes unimpaired (Friedmann 2001:71). Friedmann (2001:73) also notes the importance of information gleaned from studies of agrammatism for syntactic theory, as "the selectivity [of the deficit - OvD] imposes constraints on the theory of the normal functioning of the relevant cognitive ability: linguistic theory". The SLP's thorough understanding of syntax, and the 
application of this knowledge to the clinical process, can thus lead to the refinement of syntactic theory. Such refinement of syntactic theory can, in turn, benefit the clinical process by increasing the coherence and clarity of diagnostic measures and indicating guidelines for therapy.

As was mentioned with regard to SLI, SLPs can apply their knowledge of syntax as well as their clinical experience in order to evaluate the theoretical and empirical merit of various syntactic accounts of aphasic phenomena. Such knowledge can be applied in evaluating the above-mentioned TPH as an account of the symptoms of agrammatism. Certain proposals made within recent work in syntax raise theoretical questions with regard to the TPH. For example, a proposal has been made that there may be parametric variation among languages in terms of whether they have a split INFL (such as Icelandic) or an unsplit INFL (such as English) (cf. Thráinsson 1996). If the notion of a Split-INFL parameter is correct, the TPH would predict dissociation between tense and agreement inflection only in languages with a Split-IP parameter setting, i.e., where tense and agreement are located in separate functional categories. In languages with an Unsplit-IP parameter setting, no such dissociation would be predicted. It is clear that the SLP needs knowledge of current syntactic theory as well as an interest in empirical evidence in order to evaluate the merit of accounts such as the TPH.

It is worth noting that it is unclear what predictions the TPH would make for Afrikaansspeaking agrammatic speakers, as Afrikaans is impoverished in its overt morphology ${ }^{27}$. Specifically, Afrikaans has no overt agreement morphology on the verb, and it is unclear how one would decide whether or not there is dissociation between tense and agreement inflection in a language which has no overt agreement inflection.

Two examples of alternative accounts of the symptoms of agramamtism are of interest here. Firstly, Kemp (2000), in a study of the sentence production of an Afrikaans-speaking agrammatic subject, suggests that a deficit at the level of Spell-Out provides a better account of the data than does the $\mathrm{TPH}^{28}$. Specifically, Kemp (2000:61) proposes that both the omission and the doubling of the Afrikaans temporal AUX het in the data of the subject can be explained in terms of a deficit in spelling out temporal auxiliaries at PF - "either there is no Spell-Out, or there is excessive Spell-Out at more than one position in the chain" (cf. p. 41). A 
second account that is offered as an alternative to the TPH is that discussed by Lee (2003), on the basis of a study of the comprehension and production of Korean-speaking agrammatic subjects of three functional categories (mood, tense, and complementisers). Lee (2000:180) reports dissociation among functional categories, similar to that reported by other researchers into agrammatism (cf. Friedmann and Grodzinsky 1997). However, Lee (2000:180) also reports that structures related to higher nodes in the syntactic tree (e.g. COMP) were intact in the presence of impairment to structures related to lower nodes (e.g. T), which is the opposite of the pattern predicted by the TPH. Platzack (2001:364) also notes the vulnerability of the Cdomain, the highest structural level, noting that various groups of speakers (e.g. children with SLI and Broca's aphasics) exhibit problems with production of syntax at this high level, while producing the syntax of lower levels in a target-like manner. To account for the Korean data, Lee (2000:186) suggests that the linear position of a functional category in the clause determines its susceptibility to impairment - "the nearer to the end of the clause a functional element is located, the better it is preserved"29. The two studies mentioned here illustrate the importance of the SLP's awareness of the possibility of alternative accounts of aphasic phenomena, which must be borne in mind whenever syntactic (or any other kind of) theory is being applied in the clinical situation.

\section{CONCLUDING REMARKS}

The aim of this paper was to present and explain certain aspects of recent developments in the field of syntax and to illustrate how they are of particular relevance to the field of speechlanguage pathology. The topics covered in section 3 were aimed at providing the SLP with a basic introduction to current theory within minimalist syntax. The discussion of the application of aspects of this theory to SLI and agrammatism in section 4 illustrated how the SLP stands to gain by a clear understanding of syntax. The field of syntax (and linguistics in general) and its relevance to clinical practice may be said to have been somewhat neglected by practising SLPs in the past. It appears that many SLPs fail to consider recent developments in syntactic theory when seeking explanations for clinical phenomena. The potential contribution of syntactic theory to clinical practice, however, is great, and deserves careful consideration. It should also be noted that the development of theories of syntax which can inform the clinical process is hindered by a lack of input from practising SLPs. Only on the 
basis of such input can linguists and SLPs work together to develop theories which provide an accurate account of various clinical phenomena that are observed. 


\section{NOTES}

1 "Syntactic phenomena" here refers to language-specific facts, like the subject-verb-object word order or agreement (cf. note 23) in number between subjects and verbs in English.

2 An example of such a rule is a phrase structure rule like VP $\rightarrow \mathrm{V}$ (NP) (PP), entailing that a verb phrase consists of a verb plus an optional noun phrase and an optional prepositional phrase.

3 Note that a precise distinction between the notions of simplicity and economy is not clear from Chomsky's (1995a; 1999; 2000) recent works. It would appear that the desire for theoretical simplicity leads to a preference for economy, which gains substantive content and is expressed in derivational and representational economy (cf. section 2.3). An example of a theory-internal economy principle appears in Chomsky (2000:100), where it is suggested that the derivation (cf. note 12) accesses the lexicon only once in the selection of a lexical array (a set of lexical items, i.e. the numeration, cf. p. 33), thereby reducing operative complexity. A theory which suggested multiple accessing of the lexicon would not adhere to such a principle of economy.

4 X-bar theory, according to Hornstein, Nunes, and Grohmann (2001b:19), has to do with the phrasal organisation of syntactic objects, and ensures that these all have the same general format, e.g., Spec-head, head-complement, etc., as depicted in the tree diagram below. Cf. notes 7 and 22 for definitions of Comp (complement) and Spec (specifier), respectively.

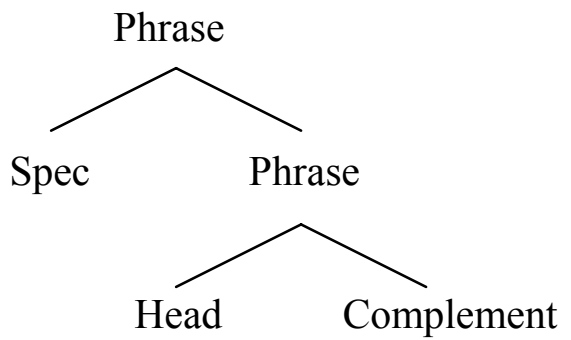

5 Logical form is "the most abstract representation of a sentence" (Matthews 1997:212), a representation which is associated with meaning.

6 A sentence is grammatical if it is formed in accordance with the grammatical rules of the language concerned (Botha 1989:186), i.e., in accordance with the set of fixed universal principles and the specific parameter settings.

7 A complement is a syntactic element which is "seen as 'completing' the construction of another element" (Matthews 1997:63). Thus, in He threw the ball through the window, both the ball and through the window are complements of threw, while the window is the complement of the preposition through.

8 There is general agreement among researchers that parameters should, ideally, and in keeping with principles of economy, be binary in nature, thus allowing a parameter to be set to one of only two values. However, there is the possibility that certain parameters may have more than two settings. 
9 Case assignment in GB theory entails the process by which abstract case is assigned to nouns and pronouns. Such case marks the role of the noun in relation to the other parts of the sentence (Matthews 1997:46). For example, she in She talks to him carries nominative case, while him carries accusative case.

10 Theta- (thematic / $\theta$-) role assignment is the process by which theta roles are assigned by predicates (e.g. verbs and some prepositions) to their arguments (e.g. nouns and NPs). For example, in Jan gee vir Marie die blomme ("Jan gives the flowers to Marie"), the verb gee ("give") has both an agent and a theme role to assign, i.e., an $\mathrm{N}(\mathrm{P})$ referent who does the giving, and an $\mathrm{N}(\mathrm{P})$ referent which is given. Hence, Jan is assigned the role of agent by the verb gee ("give"), and die blomme ("the flowers") is assigned the role of theme by the verb gee ("give"). The preposition vir ("to") also has a role to assign, namely that of goal or recipient, which is assigned to Marie.

11 Phonetic form is "the least abstract representation of a sentence" (Matthews 1997:276), a representation which is associated with sound.

12 The derivation is the process by which LF and PF representations of a linguistic expression are generated (cf. section 3.1).

13 Belletti and Rizzi (2002:32) provide the example of the expletive there in sentences like There came a man, which is necessary to express the obligatory subject but does not have referential content, and so does not have an interpretation at the level of LF, which is associated with meaning. Under Full Interpretation, the there must therefore disappear before LF. One proposed solution to this problem is the hypothesis that covert movement replaces the expletive with a contentive subject at LF, yielding A man came... as LF representation, which satisfies Full Interpretation.

14 An example is the movement of a verb to INFL to check features of tense and agreement. Under this analysis, the computational need for the features of tense and agreement to be checked drives movement.

15 The PLD comprise the utterances the child is exposed to, and so "consists (sic.) of a finite amount of information about sentences, ... restricted in scope ... and ... degenerate in quality" (Chomsky 1965: 31), due to time restrictions and other interfering factors.

16 An example of a general property of language as an organic system may have to do with physical or chemical properties of the modules of the brain where language is processed.

17 Lasnik (2002:433) suggests, for example, that competing derivations from the same numeration are compared with regard to criteria such as number of steps in the derivation and length of syntactic movement, the less economical derivations being rejected on the basis of such a comparison.

18 Note that the linguistic expression, or structural description, is the product of the derivation. 
19 An illustration of the structure dependence principle is given in Radford (1997b:13-14), where the formation of yes-no questions in English is discussed. If operations such as yesno question formation were structure-independent, a question like Can John run fast?, formed by moving can from its second position in the statement John can run fast to the first position, would lead, by analogy, to a question like *Really John can run fast? from the statement John really can run fast. The lack of evidence for such structureindependent operations in any language is the basis of the structure dependence principle, according to which the grammatical properties of lexical items must be taken into consideration in any syntactic operation. In the case of yes-no question-formation in English, it is the auxiliary verb that is moved to the position in front of the noun or NP which functions as its subject, resulting in Can John (really) run fast? (Radford 1997b:15).

Only the exceptions to the regular rules need to be learnt as individual lexical items, such as the past tense forms of English eat and throw, namely ate and threw, and the plural forms of Afrikaans lam ("lamb") and skip ("ship"), namely lammers ("lambs") and skepe ("ships").

21 The interested reader is referred to the paper by Froud (2001), in which the status of prepositions as a lexical category is investigated.

22 A specifier is the element preceding the head of the phrase containing it. For example, in the NP beautiful girls from the Karoo, beautiful is the specifier of the head noun girls.

23 Agreement entails the syntactic relation between words which are compatible. Thus, for example, the suffix -s in trees allows for number agreement in the phrase those trees, and the absence of the suffix allows for number agreement in the phrase that tree.

24 Note that, in current theory within minimalist syntax, trace theory is replaced by a copy theory of movement (cf. Marantz 1995:373), the details of which are not relevant here.

25 The "I" in I-language, according to Chomsky (1986a, 1995a), is understood to suggest "internal", "individual", "intensional", thus I-language is that instantiated in the mind of the (ideal) speaker-hearer.

26 According to Friedmann and Grodzinsky (1997:399), a literature study revealed similar patterns of dissociation between tense and agreement inflection in other cases of agrammatism.

27 In other words, various grammatical features are not overtly (phonologically) realised.

28 Note, however, the problems posed for the TPH by Afrikaans, a language impoverished in its overt morphology.

29 Note, however, that this account is based on linearity, which does not feature in minimalist syntax. 


\section{REFERENCES}

Arabatzi, M. and S. Edwards. 2002. Tense and syntactic processes in agrammatic speech. Brain and Language 80: 314-327.

Belletti, A. and L. Rizzi. 2002. Editor's introduction: Some concepts and issues in linguistic theory. In N. Chomsky. On nature and language. Cambridge: CUP. pp. 1-44.

Botha, R.P. 1989. Challenging Chomsky. The generative garden game. Oxford: Blackwell.

Cheng, L. and R. Sybesma. 1995. Language is the perfect solution. An interview with Noam Chomsky. Glot International 1 (9/10): 1, 31-34.

Chomsky, N. 1957. Syntactic structures. The Hague and Paris: Mouton.

Chomsky, N. 1964. Current issues in linguistic theory. The Hague and Paris: Mouton.

Chomsky, N. 1965. Aspects of the theory of syntax. Cambridge, USA: MIT Press.

Chomsky, C. 1970. Remarks on nominalization. In R. Jacobs and P. Rosenbaum (eds.) Readings in English transformational grammar. Massachesetts: Ginn.

Chomsky, N. 1981. Lectures on government and binding. Dordrecht: Foris.

Chomsky, N. 1986a. Knowledge of language. Its nature, origin and use. New York, etc.: Praeger.

Chomsky, N. 1986b. Barriers. Cambridge, USA: MIT Press.

Chomsky, N. 1995a. The minimalist program. Cambridge, USA and London: MIT Press.

Chomsky, N. 1995b. Bare phrase structure. In G. Webelhuth (ed.) Government and binding theory and the minimalist program. Oxford: Blackwell. pp. 383-439.

Chomsky, N. 1997a. Language and mind: Current thoughts on ancient problems (Part 1). Manuscript, MIT.

Chomsky, N. 1997b. Language and mind: Current thoughts on ancient problems (Part 2). Manuscript, MIT.

Chomsky, N. 1999. Derivation by phase. Manuscript, MIT.

Chomsky, N. 2000. Minimalist inquiries: A framework. In R. Martin, D. Michaels, and J. Uriagereka (eds.) Step by step. Essays on minimalist syntax in honor of Howard Lasnik. Cambridge, USA: MIT Press. pp. 89-156.

Chomsky, N. 2001. Beyond explanatory adequacy. Manuscript, MIT.

Chomsky, N. 2002. On nature and language. Cambridge: CUP. 
Conti-Ramsden, G. and A. Hesketh. 2003. Risk markers for SLI: A study of young languagelearning children. Journal of Language and Communication Disorders 38(3): 251263.

Cook, V. and M. Newson. 1996. Chomsky's universal grammar: An introduction. Second edition. Oxford and Cambridge: Blackwell.

De Jong, J. 2003. Specific language impairment and linguistic explanation. In Y. Levy and J. Schaeffer (eds.) Language impairment across populations: Towards a definition of specific language impairment. Mahwah: Lawrence Erlbaum Associates. pp. 151-170.

Dell, G.S. and P.G. O'Seaghda. 1992. Stages of lexical access in language production. In W.J.M. Levelt (ed.) Lexical access in speech production. Cambridge: Blackwell. pp. 287-314.

Dell, G.S. and P.A. Reich. 1981. Stages in sentence production: An analysis of speech-error data. Journal of Verbal Learning and Verbal Behaviour 20: 611-629.

Edwards, S., M. Garman, and R. Knott. 1993. The grammatical characterisation of aphasic language. Aphasiology 7(2): 217-220.

Friedmann, N. 2001. Agrammatism and the psychological reality of the syntactic tree. Journal of Psycholinguistic Research 30(1): 71-90.

Friedmann, N. and Y. Grodzinsky. 1997. Tense and agreement in agrammatic production: Pruning the syntactic tree. Brain and Language 56: 397-425.

Froud, K. 2001. Prepositions and the lexical/functional divide: Aphasic evidence. Lingua 111: $1-28$.

Garrett, M. 1980. Levels of processing in sentence production. In B. Butterworth (ed.) Language production. Volume I. New York: Academic Press. pp. 177-220.

Garrett, M. 1988. Processes in language production. In F.J. Newmeyer (ed.) Linguistics: The Cambridge survey. Volume III. Cambridge: CUP. pp. 69-96.

Grodzinsky, Y. 1984. The syntactic characterisation of agrammatism. Cognition 16: 99-120.

Grodzinsky, Y. 1986. Language deficits and the theory of syntax. Brain and Language 27: 135-159.

Hornstein, N., J. Nunes, and K.K. Grohmann. 2001a. Understanding minimalism: An introduction to minimalist syntax. Chapter 1. The minimalist project. Manuscript. 
Hornstein, N., J. Nunes, and K.K. Grohmann. 2001b. Understanding minimalism: An introduction to minimalist syntax. Chapter 2. Some architectural issues in a minimalist setting. Manuscript.

Hornstein, N., J. Nunes, and K.K. Grohmann. 2003. Understanding minimalism: An introduction to minimalist syntax. Chapter 9. Feature interpretability and feature checking. Manuscript.

Kemp, M.A. 2000. Omission and doubling of the temporal auxiliary het in the Afrikaans of an agrammatic patient. Stellenbosch Papers in Linguistics 33: 49-66.

Lasnik, H. 2002. The minimalist program in syntax. Trends in Cognitive Sciences 6(10): 432437.

Lee, M. 2003. Dissociations among functional categories in Korean agrammatism. Brain and Language 84: 170-188.

Leonard, L.B. 1995. Functional categories in the grammars of children with specific language impairment. Journal of Speech and Hearing Research 38: 1270-1283.

Leonard, L.B. 1998. Children with specific language impairment. Cambridge, USA and London: MIT Press.

Leonard, L.B. and D.F. Loeb. 1988. Government-binding theory and some of its applications: A tutorial. Journal of Speech and Hearing Research 31: 515-524.

Levelt, W.J.M. 1992. Accessing words in speech production: Stages, processes and representations. In W.J.M. Levelt (ed.) Lexical access in speech production. Cambridge: Blackwell. pp. 1-22.

Loeb, D.F. and L.B. Leonard. 1991. Subject case marking and verb morphology in normally developing and specifically language-impaired children. Journal of Speech and Hearing Research 34: 340-346.

Maartens, J. 1996. The minimalist program: An orientation. South African Journal of Linguistics Supplement 29: 5-33.

Marantz, A. 1995. The minimalist program. In G. Webelhuth (ed.) Government and binding theory and the minimalist program. Oxford: Blackwell. pp. 351-382.

Matthews, P.H. 1997. Concise dictionary of linguistics. Oxford and New York: OUP.

O'Grady, W. 1997. Syntax: The analysis of sentence structure. In W. O'Grady, M. Dobrovolsky, and F. Katamba (eds.) Contemporary linguistics: An introduction. London and New York: Longman. pp. 181-244. 
Ouhalla, J. 1999. Introducing transformational grammar. From principles and parameters to minimalism. Second edition. London: Arnold.

Platzack, C. 2001. The vulnerable C-domain. Brain and Language 77: 364-377.

Pollock, J.Y. 1989. Verb movement, universal grammar and the structure of IP. Linguistic Inquiry 20: 365-424.

Pollock, J.Y. 1997. Notes on clause structure. In L. Haegeman (ed.) Elements of grammar. Handbook in generative syntax. Dordrecht, Boston, and London: Kluwer Academic Publishers. pp. 237-279.

Radford, A. 1997a. Syntax. A minimalist introduction. Cambridge: CUP.

Radford, A. 1997b. Syntactic theory and the structure of English. Cambridge: CUP.

Rice, M.L. and K. Wexler. 1996. Toward tense as a clinical marker of specific language impairment in English-speaking children. Journal of Speech and Hearing Research 39: 1239-1257.

Rice, M.R., K. Wexler, and P.L. Cleave. 1995. Specific language impairment as a period of extended optional infinitive. Journal of Speech and Hearing Research 38: 850-863.

Shapiro, L.P. 2000. An introduction to syntax. In R. Bastiaanse and Y. Grodzinsky (eds.) Grammatical disorders in aphasia: a neurolinguistic perspective. London and Philadelphia: Whurr Publishers. pp. 1-34.

Southwood, F. 2003. Spesifieke taalgestremdheid en taalwetenskaplike teorie: 'n Evaluerende oorsig. Stellenbosch Papers in Linguistics Plus 32: 61-98.

Thráinsson, H. 1996. On the (non-)universality of functional categories. In W. Abraham, S.D. Epstein, H. Thráinsson, and C.J.W. Zwart (eds.) Minimal ideas. Syntactic studies in the minimalist framework. Amsterdam and Philadelphia: John Benjamins.

Tomalin, M. 2003. Goodman, Quine and Chomsky: From a grammatical point of view. Lingua 113: 1223-1253.

Van der Lely, H.K.J. 2003. Do hetereogeneous deficits require heterogeneous theories? SLI subgroups and the RDDR hypothesis. In Y. Levy and J. Schaeffer (eds.) Language competence across populations. Toward a definition of specific language impairment. Mahwah: Lawrence Erlbaum Associates. pp. 111-133.

Wexler, K. 1994. Optional infinitives, head movement and the economy of derivations. In D. Lightfoot and N. Hornstein (eds.) Verb movement. Cambridge: CUP. pp. 305-362. 
Zwart, C.J.W. 1993. Dutch syntax. A minimalist approach. Groningen dissertations in linguistics. 